\title{
ESTADO DO RIO DE JANEIRO: O URBANO METROPOLITANO. HIPÓTESES E QUESTÕES (*)
}

\author{
FANY DAVIDOVICH \\ Geógrafa - IBGE
}

Resumo: O espaço geográfico do estado do Rio de Janeiro teve a evolução de sua organização urbana metropolitana particularmente marcada pela atuação do poder federal da República. A presença deste poder se fez através de medidas institucionais, como no caso da mudança da capital federal para Brasília, ou da fusão dos antigos estados da Guanabara e do Rio de Janeiro; ou através de investimentos e dês-investimentos industriais, de infra-estrutura de se serviços econômicos no território fluminense e na sua região metropolitana. Esta atuação influenciava diretamente os ciclos migratórios das regiões fluminenses.

Apesar da redução histórica do papel do Estado da economia, sua presença continua particularmente forte no caso fluminense, a exemplo da produção petrolífera agora acrescida pelo pré-sal. Por outro lado, o capital acumulado, material e humano, criou um ambiente que tem favorecido o surgimento de novos empreendimentos do setor privado, inclusive de novos empresários, igualmente voltados para a indústria e para a infra-estrutura econômica. O reforço de iniciativas próprias se torna mais urgente quando o jogo político de outras unidades da Federação procura reduzir os rendimentos fluminenses, como no caso da partilha dos ganhos com o petróleo. Quanto à estrutura espacial, enfatiza-se a inadequação do modelo de centralidade urbano para uma sociedade industrial avançada, superado por padrões de cidades em rede, eixos de cidades, território policentrico, âncoras industriais.

Palavras chave: poder político e espaço geográfico, organização urbano metropolitana, cidades em rede.

Abstract: Rio de Janeiro 's geographical space and urban metropolitan organization developed influenced particularly by actions of the Federal power of the Brazilian Republic. This presence took the form of institutional measures, as the federal capital move to Brasília, or the merging of the previous states of Guanabara and Rio de Janeiro; or by industrial, and economic infrastructure and service investments and disinvestments. These actions influenced directly the migration flows of the state regions.

Although a present historical reduction of the role of the State in the economy, in the case of the state of Rio de Janeiro it is still high, as for instance, in the oil production, now turned to deep coastal waters. On the other hand, the already accumulated material and human capital provides a favorable environment for new private enterprises, included of new entrepreneurs, also turned mainly to industrial and economic infrastructure sectors. These efforts, of private initiatives become more urgent as the political play made by other federal states, aims to reduce Rio de Janeiro 's federal incomes from the oil exploitation. In regard to the spatial structure it is emphasized the inadequacy of urban centrality model for advanced industrial geographical spaces, and its replacement by other patterns, as cities in nets, urban axes, polycentric territories, industrial plates.

Key words: political power and geographical space, urban metropolitan organization, cities in nets. 
No texto a seguir, a abordagem do tema acima indicado pretende ser pautada em relações de poder com o espaço geográfico.

Relações de poder representadas, principalmente, pelo poder do Estado, considerando sua importância histórica na sociedade brasileira e, em particular, na economia.

O espaço geográfico, representado pelo Estado do Rio de Janeiro, considerando a relação especial que o Poder Político Central, sobretudo o Poder Federal, manteve com essa unidade da federação e na sua organização urbano metropolitana.

Deve ser levado em conta que a criação dessa unidade da federação resultou de uma lei complementar, emitida pelo governo federal, no regime militar, mediante a fusão dos antigos Estados da Guanabara e do Rio de Janeiro.

Deve ser levado ainda em conta que o Estado do Rio de Janeiro, exceção do Distrito Federal, constitui um espaço urbano, ímpar no território nacional, na medida que cerca de $96 \%$ de seus habitantes são urbanos, isto é, são residentes em cidades e vilas, num total de 16 milhões de indivíduos (estimativa 2009, IBGE). O Estado exibe, também, a maior concentração urbana do país, em números relativos: a região metropolitana reúne, aproximadamente, $75 \%$ da população estadual.

Pontuando a apresentação com hipóteses e questões, a idéia mesmo é a de despertar o interesse para o debate e a discussão.

\section{TRAÇOS DA EVOLUÇÃO HISTÓRICA.}

A relação do poder de Estado com esse espaço geográfico já havia sido incisiva, anteriormente à criação do atual Estado do Rio de Janeiro.

Um breve olhar sobre a evolução histórica da cidade do Rio de Janeiro traz à tona o legado da falta de um pertencer coletivo e de laços de solidariedade com o antigo Estado do Rio e as dificuldades de integração com esse território.

Vale considerar, primeiro, uma cidade que, durante séculos, dependeu e serviu de suporte ao Poder Político Central: como Cidade Real, no século XVII, como Município Neutro, no Império, como Distrito Federal, na República. Cabe deste modo, observar até que ponto se constituiu uma representação secular do monopólio do poder.

Políticas de embelezamento da polis, uma ativa função portuária associada ao saneamento da cidade, um crescimento industrial basicamente orientado para o consumo local, os serviços bancários, enfim os progressos no equipamento urbano aparelharam o Rio de Janeiro como base política e ideológica de sustentação de um projeto republicano.

Na condição de base política e ideológica serviu, também, à instalação de um novo Estado, o Estado Novo, que se propôs a inaugurar o processo de industrialização nacional, após a crise mundial de 1929. Ao mesmo tempo, começou a tomar vulto o perfil de concentração urbana na capital federal. Atendia ao interesse político de consolidação do poder com o apoio de massas urbanas, que foram estimuladas através o 
afluxo de migrantes de todo o país. Um imaginário urbano que isolava cada vez mais a cidade do Rio de Janeiro do decadente Estado vizinho.

O caráter político e ideológico da capital da República alcançou um ápice como centro do governo, sede das empresas estatais, do Banco Nacional de Desenvolvimento Econômico, dos grandes bancos públicos e privados, da bolsa de valores, como base da tomada de decisões e da direção política e econômica do país. Em oposição, a população pobre cada vez mais se viu deslocada, para áreas distantes e desprovidas de recursos de emprego, renda e equipamentos urbanos.

Foi como sede do poder federal, que partiram da cidade do Rio de Janeiro iniciativas de recuperação do Estado vizinho, agora sob a égide de uma política industrial de substituição de importações.

No antigo Estado do Rio processou-se uma relação de restauração de um território de economia estagnada, que não havia encontrado recuperação, após a decadência do café no planalto interior e a dos laranjais, na Baixada Fluminense.

O Norte Fluminense era exceção. Com seus ricos solos de massapê e seus canaviais, centrada em Campos de Goytacazes e no porto de Macaé, manteve certa independência em relação à cidade do Rio de Janeiro, particularmente antes da ligação pela estrada de ferro.

Um verdadeiro tratamento de choque foi a fundação de uma nova cidade, Volta Redonda, base da criação de uma Siderurgia Nacional. A siderurgia então concebida como "status" e alavanca de superação do subdesenvolvimento e, igualmente, como fator de Defesa e Segurança Nacional.

Fundamentais nesse processo de restauração do antigo Estado do Rio representaram a construção de estradas federais (Plano Nacional de Estradas de Rodagem- anos 50), a implantação de estabelecimentos de estatais sediadas na capital, e de indústrias de grandes empresas internacionais que possuíam sede ou representação na cidade do Rio de Janeiro.

Como antes mencionado, a restauração econômica dessa unidade da federação representou parte da política industrial então conduzida. Uma hipótese é a de que os setores industriais contemplados (distinguidos mais adiante) visaram, antes de tudo, complementar o parque industrial de São Paulo, em crescimento.

Aos propósitos desse trabalho parece suficiente a breve apresentação histórica considerada até este ponto. Vale então colocar como questão: de que modo definir a organização urbana de um território de pequena extensão, pouco mais de $43.000 \mathrm{Km}^{2}$, dominado por uma concentração urbana do porte da região metropolitana do Rio de Janeiro;

Considerando, também, que não havia o legado de uma rede de cidades, formada pela passagem do café na antiga província, a exemplo do que ocorreu em terras paulistas. Não é demais lembrar que o avanço dessa lavoura em São Paulo estimulou o da ferrovia e a criação sucessiva de cidades, pontas de trilho, bocas de sertão e assim por diante. 
Uma classificação de cidades brasileiras tem sido produzida na área de Geografia do IBGE, e veiculada na publicação Regiões de Influência de Cidades, periodicamente atualizada. Baseada na Teoria do Lugar Central, sucintamente, essa classificação remete a uma rede nacional de cidades, hierarquicamente organizadas, segundo sua posição no atendimento de bens e serviços a municípios que compõem as respectivas áreas de influência. Uma área maior ou menor, de acordo com a categoria maior ou menor do centro.

No Estado do Rio de Janeiro, nota-se que, abaixo da metrópole, alguns centros mantêm uma pequena área de influência. É válido considerar, por um lado, o poder inibidor do domínio metropolitano sobre o setor urbano do território. Mas, por outro lado, considerar também a possibilidade de uma atuação de certo modo complementar desses centros à própria metrópole, na prestação de bens e serviços comuns ou de hierarquia inferior.

Nessa rede de cidades, que compreende não só as do Estado como as da Área de Influência da metrópole carioca (Zona da Mata Mineira, Espírito Santo e Sul da Bahia), pode-se verificar que Volta Redonda, importante centro industrial, figura na mesma categoria de Cachoeiro de Itapemirim (ES), centro de uma área de economia dominantemente agrícola. Macaé, núcleo da costa do petróleo, comparece junto a Santo Antônio de Pádua, lugar central na combalida economia do Noroeste Fluminense.

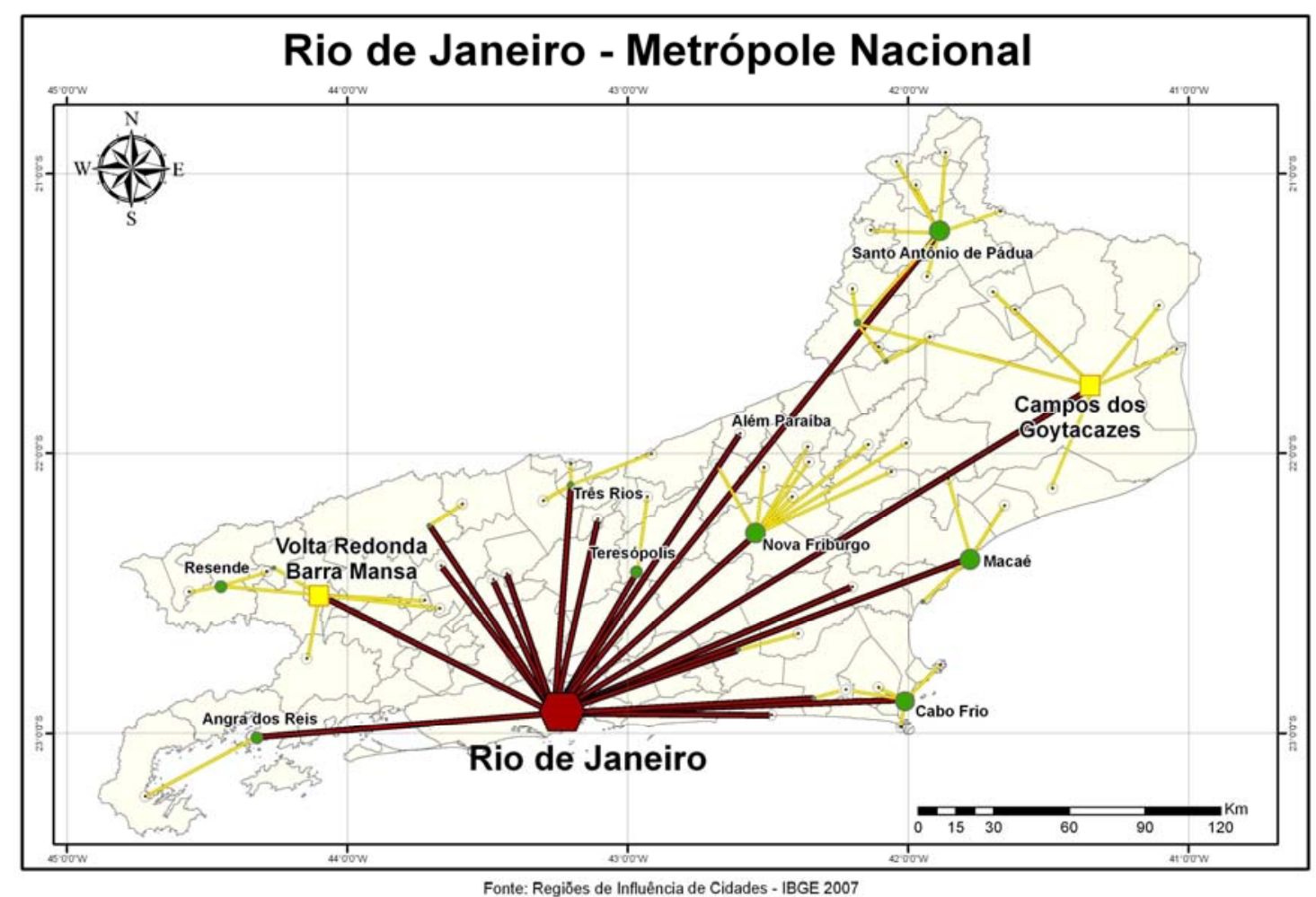


Parte-se, assim, da idéia de que, no Estado do Rio de Janeiro, a caracterização do Urbano Metropolitano pela Teoria da Centralidade não é suficiente para o conjunto de cidades, valendo então, considerar:

- a porção do território que foi contemplada por projetos federais, de estatais e do capital internacional e que representa o trecho de maior ligação com a metrópole, graças, inclusive, aos progressos na acessibilidade, à “fluidez” do espaço (Santos, M. 1994), proporcionada pelas rodovias, além da ferrovia.

- a porção do território, basicamente, o Norte e o Noroeste, que ficou relativamente à margem desse processo, de economia agrícola frágil e/ou de produção mineral (cimento, por exemplo), às quais se justapôs a exploração do petróleo e gás na fachada litorânea.

A hipótese que vai ser considerada é a de uma Organização Urbana em Eixos, representada por centros dispostos ao longo das principais rodovias e cujo crescimento teve respaldo na instalação sucessiva de plantas industriais, como foi antes mencionado. Instalação essa que remete a aquele esquema clássico da separação geográfica entre empresas, sediadas no centro principal, a capital, e estabelecimentos, distribuídos em lugares selecionados.

Em síntese, num primeiro momento, a Organização Urbana em Eixos assim pode ser compreendida:

- o eixo da rodovia Presidente Dutra, a BR-116, onde se formou a conurbação Volta Redonda-Barra Mansa, importante centro siderúrgico, e mais tarde, Resende, com o setor automobilístico;

- o eixo da rodovia Rio-Santos, a BR-101 sul, onde se sobressaíram Angra dos Reis, com a Usina Nuclear e a Construção Naval e a orla metropolitana, com a Valesul e mais tarde a Cosigua; e a BR-101 norte, onde veio a se desenvolver Macaé, frente à exploração do petróleo e do gás natural;

- o eixo da RJ-106 que comunicava com a região de Cabo Frio - Araruama, onde se estabeleceu a Companhia Nacional de Álcalis e, posteriormente, a expansão do turismo; - o eixo da BR-040, que contemplou o município de Três Rios, onde se localizou a fábrica de vagões da Companhia Santa Matilde, e aumentou as ligações com a Zona Serrana.

Alguns pontos devem ser assinalados:

- primeiro, que o reducionismo da análise não compromete a idéia central que é, precisamente, a de remeter a determinados traços do quadro urbano fluminense; considera-se que a hipótese em questão poderia ser pensada como um modelo, necessariamente reducionista.

- segundo, que a organização urbana em eixos coloca em discussão a caracterização das cidades apenas pela função de centralidade, já que teriam se constituído, basicamente, em Pontos de Apoio da metrópole, ou seja, em Lugares Descontínuos do Espaço Metropolitano. Lugares para onde seguiu a desconcentração de indústrias e de outras atividades, lugares que "construíram” o Entorno da metrópole antes da Periferia Imediata, ao contrário do que se processou em outras regiões metropolitanas do país. 
De fato, a observação empírica revela que determinadas indústrias serviram, de “âncoras” por assim dizer na estruturação de periferias metropolitanas; Trata-se da siderurgia, da química, (refinaria e petroquímica) e da automobilística, secundadas pela construção naval, indústrias da chamada "velha economia", mas que ainda tem representação na Bolsa de Valores de N. York. Este é um perfil que pode ser observado nas regiões metropolitanas de Porto Alegre, Belo Horizonte, São Paulo, Salvador, parcialmente em Curitiba ou Recife, e pleiteada nas demais.

Na região metropolitana do Rio de Janeiro, o município de Duque de Caxias foi contemplado com um setor automobilístico, que teve curta duração e que encontrou êxito no Vale do Paraíba, mas mantêm a refinaria e, mais recentemente, o pólo gásquímico. A construção naval, às margens da Baía de Guanabara, permaneceu, durante muito tempo, estagnada, recuperando fôlego apenas recentemente. A siderurgia foi somente implantada no governo Geisel, largamente superada, no tempo, pela Companhia Siderúrgica Nacional, no Entorno Metropolitano.

A disposição espacial em eixos veio confirmar a incisiva prevalência da atuação federal numa parte do território fluminense. Correspondeu a um projeto que visou instrumentalizar o trecho do Estado do Rio de Janeiro, de maior proximidade entre os principais pólos econômicos do país - São Paulo e Rio de Janeiro. O sítio da Companhia Siderúrgica Nacional correspondeu a essa estratégia, a serviço dos mercados consumidores mais importantes da produção do aço.

Não haverá, certamente, exagero em reconhecer que uma parte do território fluminense se constituiu em plataforma logística para a implantação de Investimentos Estratégicos de Interesse Nacional: a Siderurgia, a Companhia Nacional de Álcalis, as Indústrias do Petróleo, a Usina Nuclear. É valido reconhecer, também, o mesmo caráter estratégico no investimento estrangeiro, sobressaindo-se as indústrias do Material do Transporte: Construção Naval, Automobilística, Ferroviária.

Tais considerações fazem lembrar Lefébvre (1974), que nos diz que o Espaço é essencialmente Político, Estratégico e Ideológico, ou seja, o Espaço como Instrumento do Poder. Vale assim, identificar um caráter estratégico e político nesse trecho do território fluminense, onde se encontra a Academia Militar das Agulhas Negras e onde Angra dos Reis e Volta Redonda foram erigidos em municípios de Segurança Nacional, até os anos 80 .

\section{PERMANÊNCIA / MUDANÇA NO ESPAÇO GEOGRÁFICO FLUMINENSE.}

A criação do atual Estado do Rio de Janeiro (1975) correspondeu a uma relação específica do Poder Federal com o espaço geográfico do Sudeste. Representou um ato autoritário e de caráter geopolítico do regime militar, no sentido de promover a unificação do mercado nessa região, constituída em core-área avançada do país, e de estabelecer um equilíbrio regional, ante o poder econômico alcançado pelo Estado de São Paulo. 
Por sua vez, a criação da região metropolitana, igualmente por lei complementar (1974), representou a institucionalização de uma concentração urbana já existente, através das ligações entre cidade central e municípios vizinhos. Mas correspondeu, também, a uma política urbana, associada a um novo processo de acumulação capitalista no país. Processo esse que envolveu uma retomada da substituição de importações, agora, baseada em bens intermediários e no desenvolvimento tecnológico. Nessa perspectiva, um conjunto hierarquizado de cidades, funcionalmente interdependentes, representava um recurso básico para a pretendida realização de metas comuns, de princípios de equilíbrio e de controle do sistema. As metrópoles, cabeças dessas redes, davam suporte a uma política de integração do território nacional e de desenvolvimento econômico, com respaldo em uma sociedade dominantemente urbana.

Mudanças ocorreram nas relações do Poder com o espaço geográfico fluminense, a partir da transferência da capital federal para Brasília.

Na condição de Estado da Guanabara, Cidade-Estado, o Rio de Janeiro conheceu períodos de administração eficiente, que introduziu grandes melhorias no equipamento urbano, a exemplo do abastecimento de água, da expansão viária e da multiplicação de estabelecimentos de ensino da rede pública. Perdas do gasto público e da massa salarial, resultantes da mudança da função de capital federal para Brasília, foram compensadas, de certo modo, pelas receitas concomitantes de estado e de município que passou a auferir. Mas, ao mesmo tempo, mais uma vez tornou patente a distância entre a cidade do Rio de Janeiro e o Estado vizinho.

A extinção da Cidade-Estado se fez por simples decreto e implicou, entre outros problemas, a eliminação de uma representação do Rio de Janeiro no Senado nacional, reduzida a duas cadeiras, apenas. O novo Estado do Rio de Janeiro sagrou a cidade do Rio de Janeiro como município e capital dessa unidade da federação. Condição essa que envolveu dificuldades de ajuste a uma situação político-administrativa inédita, que expressava total oposição ao tradicional pensar político nacional da antiga capital do país.

Uma situação que se agravou com a crise fiscal e financeira do Estado Nacional, nos anos 80 e 90. O segundo choque do petróleo (1979) e a elevação dos juros americanos contribuíram para denunciar fragilidades estruturais do modelo, sustentado pelo regime militar. Ou seja, a ruptura de um padrão expansivo da economia nacional que envolveu a perda da importância do Estado na economia, com a superação decisiva de um modelo de desenvolvimento, baseado no binômio gasto-investimento público.

Pesquisas recentes têm indicado que, no período de 1990 - 2003, o crescimento médio do PIB brasileiro não teria passado de $1.8 \%$, apresentando quedas em alguns anos, de $0.5 \%$ em 92 ou de $0.2 \%$ em 2009, por exemplo. Portanto, nada que se compare aos explosivos crescimentos dos anos 70, quando o do PIB nacional logrou alcançar a quase $14 \%$, infelizmente associado a um período de tortura, de desaparecimento e de degradação de muitos brasileiros.

Pode-se observar, assim, que a produção urbano industrial do território fluminense correspondeu, precisamente, ao período de maior crescimento econômico do 
país, o período Getúlio - Geisel. A crise do Estado nacional, que não ocorreu apenas no Brasil, colocou em pauta a fragilidade da classe empresarial privada do país e da fluminense, em particular. Uma unidade da federação na qual o setor governo atuou como um componente quase autônomo da renda e como fator principal da formação da economia regional mais urbanizada do país. Compreende-se, deste modo, que o Estado do Rio de Janeiro tenha sido particularmente afetado pelo recuo do gasto público e pela contração da massa salarial; abrigando uma forte presença de assalariados do governo, a metrópole carioca foi então estigmatizada como Vanguarda da Crise.

A mudança da capital para o planalto central não significou interrupção de investimentos estatais no Rio de Janeiro. Além dos referentes à Petrobrás ou à Vale do Rio Doce, citam-se, entre outros, os das Centrais Elétricas, Furnas, Companhia Brasileira de Recursos Minerais, Eletrobrás, Telebrás, todas sediadas na metrópole. O II Plano Nacional de Desenvolvimento, nos anos 70, deu impulso ao fortalecimento tecnológico da cidade do Rio de Janeiro, com a instalação de setores de ponta, como a Nuclebrás, a Biotecnologia na Fundação Oswaldo Cruz, ou a Companhia Brasileira de Computadores, em Jacarepaguá.

Mas, a retirada dos incentivos fiscais e creditícios e o processo de privatizações afetaram, severamente, diversas estatais, como a Companhia Nacional de Álcalis, a Light, além de várias empresas públicas estaduais; a Companhia Siderúrgica Nacional deparou-se com uma situação quase falimentar, a Valesul e a Usina Nuclear enfrentaram estagnação. Às margens da baía de Guanabara, foram extintas, as instalações navais da japonesa Ishikawagima e desativados tradicionais estaleiros nacionais, com a falência dos Fundos da Marinha Mercante; encerrou, também, as operações a Companhia Santa Matilde.

A autonomia estadual, conferida pela Constituição de 1988, não implicou alteração da estrutura territorial legada pelo período desenvolvimentista nacional. Os investimentos, que se seguiram com a abertura da economia e as privatizações, vieram se estabelecer nos mesmos lugares de antes, confirmando o caráter seletivo do capital. De fato, indústrias e outras atividades privilegiaram cidades que já contavam com melhor infra-estrutura e recursos técnicos, inclusive pessoal treinado, que asseguravam menores custos de produção. Compreende-se, assim, a força de permanência do traçado espacial do território fluminense.

De fato, o avanço das privatizações ou das iniciativas privadas novas, que não excluiu investimento estatal, contemplou, mais uma vez, o Entorno metropolitano, o território dos eixos, que tem um limite: a distância extrema de duas horas e meia, aproximadamente, a partir da capital, por asfalto. Mas, a periferia da metrópole, durante longo tempo negligenciada pela grande indústria, foi também contemplada e não apenas em Duque de Caxias. Esse município se distinguiu dos demais da região metropolitana desde a implantação da Fábrica Nacional de Motores, até a Refinaria Duque de Caxias e do Pólo Gás-Químico, mais recente, ou a do Instituto Nacional de Pesos e Medidas (INPM).

Uma análise da "renovação" do Entorno permitiu assinalar: 
- no eixo da BR-116, a Dutra, a privatização da Companhia Siderúrgica Nacional atraiu a colaboração da Thyssen Krupp e da Galvasud na fabricação conjunta de determinados tipos de aço, e a da Siemmens, para a criação de uma Termelétrica; somente se manteve a parceria com a Galvasud. Em torno da planta de caminhões e ônibus da Volkswagen (Resende) foi formado um pólo da indústria automobilística, com a vinda da PeugeotCitroën para o novo município de Porto Real. Pólo esse que passou a contar com a fábrica de vidros planos da Guardian, multinacional, e para onde está prevista a construção de um parque de fornecedores junto à unidade de produção, contemplados com benefícios fiscais (já estão identificadas as empresas Maxion, Rondon e Arvin Meritor).

Uma observação que cabe é a de que até que ponto o desenvolvimento automobilístico fluminense, próximo à fronteira com São Paulo, seria uma extensão de indústrias congêneres localizadas no Vale do Paraíba daquele Estado. Mas, ainda em Resende, cabe mencionar a presença de uma estatal, como é a Usina de Enriquecimento de Urânio, empreendimento que estabelece conexão dessa parte do território fluminense com o litoral da Usina Nuclear.

- No eixo BR-101, a Rio Santos, capitais de Cingapura substituíram a holandesa Verolme nos estaleiros de Angra dos Reis, onde se encontra em licitação a implantação da Usina Angra 3, ou seja, mais um investimento estratégico de interesse nacional. Por outro lado, o Turismo, a segunda residência, a multiplicação de pousadas e hotéis imprimem forte marca nesse litoral, o da Costa Verde. Atividades que encontram extensão no litoral norte. De fato, após a desativação da Companhia Nacional de Álcalis e a construção da ponte Rio-Niterói e a da RJ-106, multiplicaram-se os loteamentos naquela área e os empreendimentos orientados para o turismo, consagrando a Região dos Lagos e a Costa do Sol.

- No eixo da Zona Serrana grandes mudanças se fizeram sentir, na medida em que, foram eliminadas as indústrias têxteis tradicionais, apropriadamente adaptadas à paisagem montanhosa, e na medida em que suas principais cidades passaram a ser invadidas pela especulação imobiliária e pela degradação ambiental. Petrópolis mantém, atualmente, o Laboratório Nacional de Computação Científica, parte de um projeto que acalentou a formação local de uma Tecnópolis. Teresópolis conta com uma importante firma de gestão empresarial, que sustenta uma rede nacional e venda de projetos para o exterior (exemplo de Angola). Em Nova Friburgo as antigas têxteis foram substituídas por um pólo de confecção de moda íntima, que comporta uma ativa rede de representações comerciais.

- Cabe igualmente menção ao eixo de turismo histórico e rural que se desenvolve, principalmente em torno de antigas fazendas de café, ao qual se associa o crescimento do número de clínicas de saúde e emagrecimento. Atividades essas que tem contribuído para reanimar a vida urbana das cidades localizadas nesses municípios, a exemplo de Valença, Paraíba do Sul ou Rio das Flores, sem esquecer da função universitária de Vassouras. 
No tocante à Periferia Metropolitana, pode ser notada a formação de um pólo siderúrgico em torno da baía de Sepetiba: a Companhia Siderúrgica da Guanabara, privatizada pela Gerdau, e a Companhia Siderúrgica do Atlântico, investimento novo da Thyssen Krupp (desligada agora da CSN) em associação com a Vale do Rio Doce, e localizada em Santa Cruz, na Zona Oeste do município do Rio de Janeiro. No lado oposto da região metropolitana, no município de Itaguaí, encontram-se a Embratel, de capitais privados, e o Complexo Petroquímico do Estado do Rio de Janeiro, o COMPERJ, de capital estatal, em construção. Cabe ainda menção ao Arco Metropolitano, uma via de 147 km, que deve unir o porto de Sepetiba à BR-101 e à BR040, projeto já incluído no orçamento da União.

O conjunto de empreendimentos investidos no Estado do Rio de Janeiro contrariou, por um lado, a propalada idéia do esvaziamento econômico, a partir dos anos 80. Mas, por outro lado, é preciso reconhecer que a participação relativa dessa unidade da federação na produção industrial do país declinou de $27.9 \%$ para 9.7\%, no período 1939 - 1980.

Argumentos diversos têm apontado a dificuldade de desenvolver complexos industriais integrados, ou a de captar setores de ponta, associada à prevalência de níveis salariais elevados e a custos monetários mais altos da cesta de consumo, entre outros fatores. Fatores esses relacionados, basicamente, ao modelo de poder que presidiu os rumos da economia fluminense.

A exploração do Petróleo e do Gás Natural, na bacia de Campos, passou a ser o principal esteio da economia do Estado do Rio de Janeiro. Mais um Investimento Estratégico de Interesse Nacional, que tem conferido novo impulso ao litoral norte fluminense, onde Macaé se constituiu em base logística da exploração submarina do petróleo. Entre 1996 e 2001, a participação da extração desse recurso no PIB fluminense saltou de $17 \%$ para $52.4 \%$, enquanto a da indústria de transformação declinou de $82.4 \%$ para $47.3 \%$, naquele período. De fato, é nessa parte do litoral brasileiro que se encontra a província petrolífera mais importante do país: $81 \%$ da produção do petróleo e $42.5 \%$ da de gás natural.

Novas perspectivas para esse eixo de organização do território fluminense vêm de ser levantadas com a exploração do Pré-Sal, notadamente pela participação de uma iniciativa privada nacional moderna, como é a do empresário Eike Batista. Alude-se, em particular, ao mega complexo portuário industrial, o Porto do Açu, em construção, no município de São João da Barra. Iniciativa essa, viabilizada pelo mercado de capitais, que assegura melhores possibilidades de investir na infra-estrutura, e que tem contado com a relativa facilidade de desapropriação dos terrenos necessários, proporcionada pelo governo.

As perspectivas do Pré-Sal implicam a necessidade de novos investimentos, não só em transporte, comunicação, comércio e serviços, como em indústrias capacitadas a produzir equipamentos mais sofisticados. Ou seja, é um crescimento econômico que introduz a expectativa de uma ampla cadeia produtiva, onde se sobressai a fabricação de plataformas, navios, “offshore” e navios tanque, sondas e assim por diante. 
Por ora, os efeitos multiplicadores dessa economia têm sido relativamente modestos. Algumas iniciativas reportam-se à construção naval, retomada, agora, com o Programa de Modernização e Expansão da Frota (PROMEF): estaleiros de Niterói e de Angra dos Reis têm recebido encomendas da Petrobrás, o que anima, também, a fabricação de peças e placas metalúrgicas (em São Gonçalo, por exemplo). Devem ser, igualmente, considerados projetos de indústria relacionados ao petróleo que devem contemplar o município de Campos de Goytacazes.

Mas, a contribuição mais importante da exploração do petróleo e do gás natural para a economia fluminense tem sido a receita dos "royalties", representando um aporte de 7 bilhões de reais por ano, ou seja, $46.48 \%$ de um total de 14.6 bilhões de reais.

Contrastes marcantes se fazem presente no Norte e Noroeste fluminenses, regiões de economia deprimida, em grande parte, mais adiante comentadas.

A exposição até aqui conduzida leva a considerar outras manifestações de poder no território fluminense.

\section{OUTRAS MANIFESTAÇÕES DE PODER NO TERRITÓRIO FLUMINENSE.}

As grandes empresas seriam, certamente, representação de um exercício de poder, ante o grau de autonomia de ação de que dispõem.

A cidade do Rio de Janeiro é sede das duas maiores e gigantescas empresas do país: a Petrobrás, estatal e a Vale do Rio Doce, privada, ambas de categoria internacional. Seus investimentos em território fluminense têm sido relativamente reduzidos. Sabe-se, claro, de seus projetos de proteção ambiental e de patrocínio cultural. Sabe-se, igualmente, que implantações como a Refinaria Duque de Caxias/Pólo Gás-Químico ou como o atual Complexo Petroquímico do Rio de Janeiro contribuem para o aumento da arrecadação de impostos para o município e para o Estado; mas também se sabe que as indústrias do petróleo não se constituem em fonte expressiva de emprego, oportunidades maiores surgem no período de obras de construção dos complexos. Com respeito aos "royalties", a possibilidade de reduzir a participação que detém na economia estadual se configura como uma perspectiva desastrosa para os cofres públicos. Tema que será retomado em trecho mais adiantado do trabalho.

O que se pretende salientar é a idéia de Enclave que implantações da grande empresa têm representado com respeito aos municípios onde se localizam. Ou seja, são plantas industriais que estabelecem relações escassas com o entorno, mas que exercem grande influência na economia extra-local. O exemplo da Companhia Siderúrgica Nacional é significativo. De tal monta é o poder econômico dessa empresa que uma queda na produção tem forte impacto não só na arrecadação municipal, no caso, a de Volta Redonda, como em toda a economia do Sul fluminense, como ocorreu em janeiro de 2009.

A liberdade de ação de que desfrutam essas empresas pode ser aferida no exemplo da Companhia Siderúrgica do Atlântico (CSA). Com efeito, esse empreendimento logrou impor suas regras e seus interesses em contratos de trabalho 
(importação de trabalhadores chineses e de técnicos alemães) e em programas de proteção ambiental que utilizam tecnologia particular.

Outras manifestações de poder devem ser consideradas, além do âmbito da empresa. Alude-se à presença do poder local, na medida de sua influência nos próprios rumos da vida regional. Um caso exemplar remete ao Norte fluminense.

O desmembramento entre o Norte e o Noroeste fluminenses, estabelecido pelo governo Moreira Franco, com vistas à efetivação de planos regionais, contou com o apoio de lideranças políticas tradicionais de Campos de Goytacazes, contrariando a postura de diferentes setores da sociedade local. A imprensa, representando as vozes do conflito social subjacente a essa subdivisão regional, denunciou, persistentemente, a posição negativa do poder de Campos para a formação de uma consciência regional, uma vez que se utilizava dos municípios próximos apenas como suporte de reivindicações em beneficio próprio.

Acresce que, ainda no período daquele governo, a idéia de um pólo petroquímico foi amplamente acalentada e disputada pelos municípios de Duque de Caxias e de Itaguaí (região metropolitana do Rio de Janeiro). No intuito de dar novo alento à depauperada economia do Norte fluminense, o "locus" de instalação privilegiaria o município de Campos de Goytacazes. A proposta teria sido recusada pela elite local, representada principalmente por usineiros, seja pela previsível concorrência em torno da mão de obra, seja pela elevação do salário médio regional que aquele empreendimento industrial deveria proporcionar.

Trata-se, portanto, de um exemplo particular de afirmação de fatores de inércia naquela porção do território estadual, sob a decisiva influência de um poder local. A idéia do pólo petroquímico fluminense não vingou, na ocasião, devido, em grande parte, a desentendimentos do governo do estado com a esfera federal, seguindo, então, o empreendimento para Triunfo, no Rio Grande do Sul, terra de Brizola.

Outra manifestação de poder, que merece menção, é a da Administração Pública, neste caso em nível nacional, pela participação que detém na economia de grande número de unidades da federação e de municípios. Atinge a mais de $90 \%$ em Estados do Nordeste e do Norte do país. No Estado do Rio de Janeiro, diversos municípios dependem de repasses públicos das prefeituras; causa espécie que o Rio de Janeiro, ao contrário de centros do Sudeste e do Sul, conta com 13.2\% dessas receitas, ou seja, figura, praticamente, na média da participação nacional, que é de 13.3\%. A dependência econômica e financeira dos cofres públicos implica sujeição a quedas eventuais desses recursos, acarretando condições negativas para iniciativas empreendedoras.

Tais considerações introduzem à observação a seguir, que diz respeito ao posicionamento do Rio de Janeiro com relação ao contexto atual da globalização dos mercados, o que, afinal, não se dissocia das questões de poder. 


\section{GLOBALIZAÇAO E RIO DE JANEIRO EM QUESTÃO.}

Com as perspectivas de realização da Copa 2014 e das Olimpíadas de 2016, o então prefeito do Rio de Janeiro, proclamou-a como Cidade Global, dadas as grandes possibilidades que aqueles eventos iriam oferecer para o desenvolvimento da infraestrutura, do emprego e a atração de novas empresas.

É preciso, porém, apurar o conceito de Cidade Global, o que escapa aos propósitos desse texto. Vale, tão somente observar que implica na capacidade de comando em nível mundial, ou seja, em força motriz, capaz de imprimir novos rumos à sociedade do planeta. S. Sassen primeiro definiu a Cidade Global como um Eixo aquele onde o Sol nunca se põe - compreendendo Tóquio, Nova Iorque e Londres, numa clara referência ao primado da velocidade da informação, no comando das finanças mundiais. Outros centros seriam partes complementares desse eixo ou importantes nós de articulação de grandes redes internacionais.

Deve ser reconhecido que a cidade do Rio de Janeiro não dispõe, por ora, de tais atributos. Uma iniciativa, como a do Teleporto, que se pretendia o maior Centro de Telecomunicações da América Latina, não teve prosseguimento. Acresce que também não se observa, no Rio de Janeiro, um desenvolvimento econômico balisado na expansão de serviços avançados, particularmente a serviço da produção, como reza o paradigma atual. Ao contrário, a cidade tem perdido serviços e funções; a mudança da capital envolveu, por exemplo, a transferência de serviços especiais, vinculados à função de centro de decisões nacionais e de negociações de interesse internacional, sem as devidas compensações. No tocante à globalização financeira, o Rio de Janeiro tem sofrido um processo declinante, nesse setor. Em 1939, reuniam-se, na cidade, 33\% das matrizes das instituições financeiras atuantes no país, e, três décadas, mais tarde, somente 18\%, enquanto 34\% têm sede em São Paulo. Um ato decisivo foi a perda da Bolsa de Valores do Rio de Janeiro; não resultou, apenas, da operação golpista de um especulador ou da força de atração da praça de São Paulo, mas, principalmente, do reduzido volume de negócios na ex-capital da República.

É difícil, além disso, atribuir o "status" de Cidade Global a uma cidade, cuja receita acusa ainda tal dependência dos cofres públicos, sem contar os problemas de pobreza e de violência ou as deficiências do equipamento urbano.

Outros aspectos devem ser também considerados, quando se coloca em questão a relação do Rio de Janeiro com a globalização, e que dizem respeito ao território do Estado.

A referência à Organização Urbana em Eixos pretendeu questionar a definição de uma rede de cidades hierarquicamente estabelecida com base, apenas, na centralidade, nessa porção de espaço fluminense. Os centros assumidos, então, como partes descontínuas do espaço metropolitano, expressando uma divisão territorial do trabalho: na metrópole, mudanças da estrutura produtiva, com a prevalência do setor serviços e fatores negativos para a atividade industrial (congestionamentos, elevação do 
preço do solo, entre outros), enquanto certas cidades passaram a ser alvo da desconcentração da indústria, principalmente.

Um outro olhar sobre esta organização urbana permite levantar novas questões.

A teoria atual confere ênfase à projeção das Cidades em Rede, e não como redes de cidades, decorrência mesmo do progresso da telemática e da velocidade das comunicações no mundo de hoje, além de outros fatores.

No caso fluminense, as grandes empresas sustentam redes reconhecidamente globalizadas. A Companhia Siderúrgica Nacional mantém minas de carvão e de minério de ferro, fábricas de cimento e de metalurgia, distribuídas em diversos Estados e na América do Sul, além de siderúrgicas adquiridas em Portugal e nos Estados Unidos, com as quais desenvolve produção complementar. A Petrobrás tem presença em 28 países e conta com mais de 1 milhão e 600 mil fornecedores no território nacional. A Vale do Rio Doce detém poder de decisão na fixação de preços do minério de ferro, em nível mundial. Thyssen Krupp, a Volkswagen (hoje substituída pela MAN Latin America, provavelmente uma subsidiária, também alemã), a Peugeot-Citroën são partes de redes de escala planetária.

A hipótese em pauta, faz considerar que as cidades onde se localizam tais empreendimentos estão inseridas nas redes das grandes empresas, enquanto "meio para a prática da empresa” (Becker, B. , 2009). Ou seja, apenas pela sua condição urbana, elas não se configuram como "cidades em rede".

Mas, paralelamente, cabe considerar que estes centros têm se desenvolvido como "cidade de porte médio", exibindo certo nível de centralidade urbana. Trata-se, portanto, de cidades que já apresentam um grau de estrutura social e produtiva, que, seguramente, uma dada autonomia municipal (Constituição, 1988) proporcionou. Em muitas delas tem lugar a expansão de emprego, principalmente no setor de prestação de serviços, que vem de compensar, de algum modo, as dispensa de mão de obra decorrente da modernização de indústrias.

A despeito de diferenças no ritmo de crescimento populacional, (maior em Angra dos Reis e Macaé do que em Volta Redonda, por exemplo) cabe reconhecer a formação de um conjunto significativo de centros urbanos nessa parte do território fluminense. Conjunto esse que, agregado à metrópole, corresponde, certamente a um Território Policêntrico (Hall, P. , Pain, K. , Edit. , 2006), territorialidade que tem progredido no contexto urbano da globalização e que constitui, seguramente, uma designação mais adequada do que a de Região Polinucleada, empregada a respeito da região metropolitana de São Paulo e seu Entorno (Davidovich, F. , 1978). 


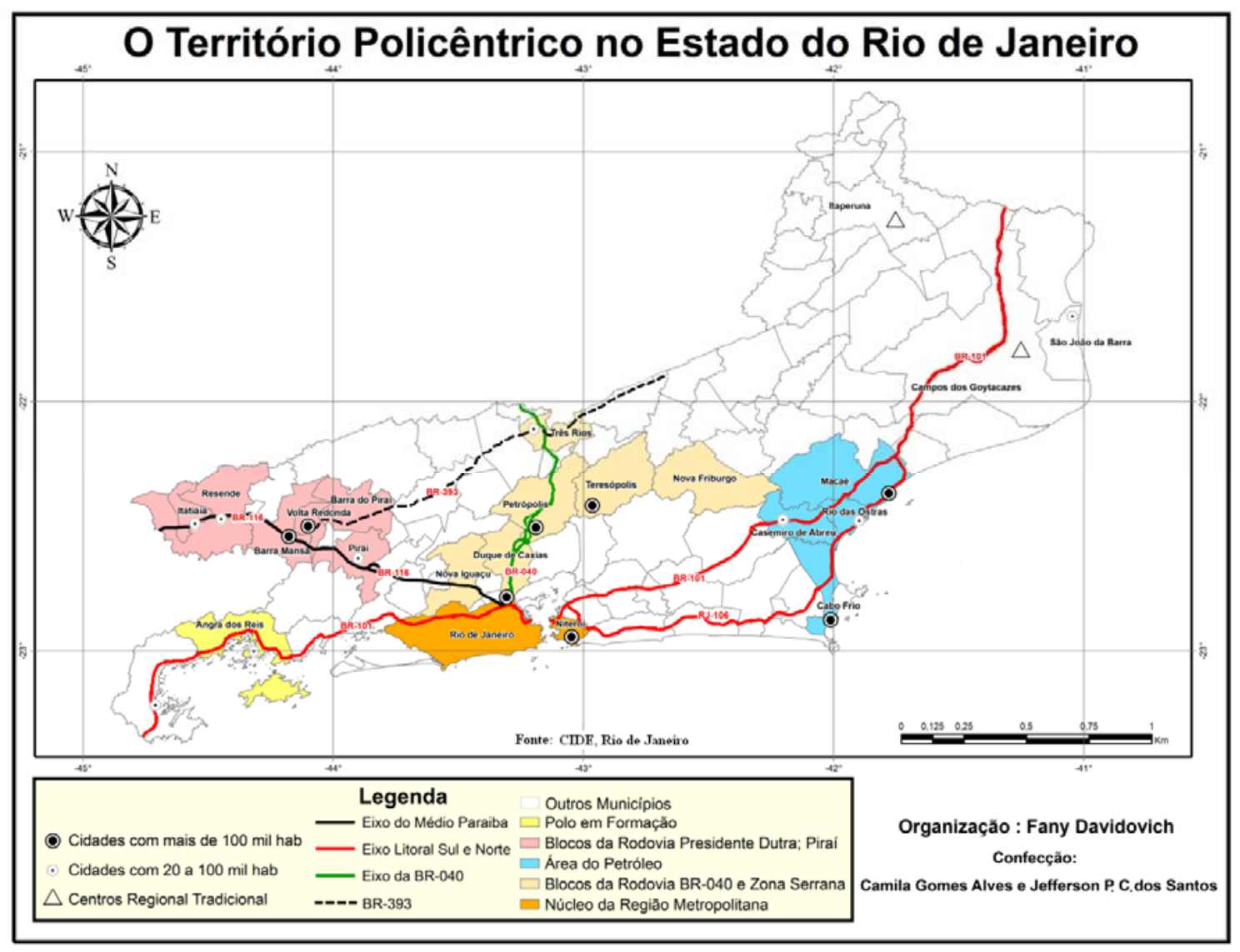

O tema das relações do Rio de Janeiro com o movimento da globalização envolve, ainda, outras considerações. Conotação particular adquire a atividade da mineração na economia nacional, alcançando elevadas cotações na Bolsa de Valores. Um crescimento que vem ao encontro do aumento mundial da demanda, em que se sobressai, largamente, a China. Em 2009, a exportação para aquele país acusou um salto de $34 \%$.

Capitais chineses têm considerado a aquisição de ativos de mineração no país, dependendo da logística, da qualidade de minério de ferro e da produtividade da mina. Na verdade, já é um processo em curso no território nacional, processo esse cujo objetivo primeiro é o de atender às siderúrgicas chinesas, efetivando, deste modo, um movimento de verticalização da produção, que associa minério e aço. A China consume 1.3 bilhão de toneladas de minério de ferro por ano, mas produz, apenas, 350 milhões de toneladas.

Interesses asiáticos, de maneira geral, têm contemplado o Estado do Rio de Janeiro. Ainda se fazem presentes na construção naval, como foi, no passado, a da japonesa Ishikawagima (em via de recuperação pela Petrobrás) e, atualmente, a Brasfelds, de capitais de Cingapura, que substituiu a holandesa Verolme, nos estaleiros de Angra dos Reis. Mais recentemente, capitais asiáticos contribuíram para a recuperação econômica do município de Piraí (mais uma vez, o eixo da Dutra), através 
de investimentos na informática, que devem se estender ao município de Rio das Flores (iniciativa estadual).

O interesse maior na mineração tem acionado a necessidade de promover a logística, que envolve a infraestrutura de transporte e de portos. Além da compra de jazidas de ferro, capitais asiáticos têm em vista, também, associações ou participações com empresas brasileiras, no país. Assim, ao empreender a abertura do capital, a Companhia Siderúrgica Nacional colocou à venda $40 \%$ da NAMISA a um consórcio formado pela Nippon Steel (japonesa) e pela Posco (coreana). Um dos projetos diz respeito à fabricação de aços longos, em Itaguaí, na orla metropolitana, mais uma vez privilegiando a territorialidade dos eixos e metrópole. Menção particular cabe ao empreendimento de E. Batista, no Porto do Açu, onde estabeleceu parceria com a Wuhan Iron and Steel em um projeto de construção de uma siderúrgica gigante, o maior investimento da China, no exterior. Deve ser observado que as perspectivas de fornecimento de material e de equipamento, levantadas pela exploração do Pré-Sal, representam uma das bases daquela atividade. Mas, uma outra base corresponde à exportação de excedentes da produção siderúrgica.

Cabe, portanto, assinalar a grande mobilização de empresas em torno do aparelho portuário do Estado do Rio de Janeiro. Através a BR-393, o minério de ferro procede de Minas Gerais e segue para Volta Redonda, de onde é encaminhado para o porto de Angra dos Reis. A MRS detém um porto de certo modo cativo em Mangaratiba. Vale do Rio Doce e Companhia Siderúrgica Nacional tem sido acusadas do exercício de monopólio no tocante ao porto de Sepetiba; nessa área, está prevista a construção do porto do Sudeste, mais, um projeto de E. Batista, que visa, precisamente, a atender a mineradoras com dificuldades de acesso a aquelas instalações.

A posição que a produção siderúrgica e o trânsito de minérios ocupam em território fluminense, leva a considerar duas questões:

- primeiro, faz colocar em pauta um elemento logístico de relevância particular no contexto da globalização, como é o aparato portuário e seu condicionamento para a otimização do desempenho, visando a exportação;

- segundo, remete à idéia de que até que ponto o território fluminense estaria sendo instrumentalizado como uma Plataforma de Exportação, que envolve principalmente produtos siderúrgicos e minério, procedente, sobretudo, de Minas Gerais. Situação essa que significa uma inflexão com respeito a um passado recente, quando predominou uma estrutura produtiva orientada para o mercado nacional.

Investimentos estratégicos de interesse do país têm ainda expressão no Estado, a exemplo das atividades relacionadas à energia nuclear ou à exploração submarina do petróleo, em camadas cada vez mais profundas. Mas é inegável a repercussão da ênfase atual emprestada à exportação do minério de ferro, em particular, e a de produtos da siderurgia do território fluminense.

Uma questão válida é a de até que ponto tal diretriz pode compatibilizar-se com a necessidade de ampliar investimentos para atender à crescente demanda do mercado interno. Basta lembrar o papel do consumo das famílias e do governo no relativo 
amortecimento dos impactos da crise mundial de 2008 - 2009 na economia do país; consumo esse, cuja participação no PIB nacional alcançou a 62.8\%, o maior resultado da década, constituindo-se em um esteio seguro, ante as dificuldades de competição, enfrentadas principalmente com a China e a Índia, no mercado internacional.

\section{QUESTÕES EM PAUTA NO ESTADO DO RIO DE JANEIRO}

A evolução histórica dessa unidade da federação tem sido pontuada por uma trajetória de perdas. Já houve referência anterior às sofridas perdas pela cidade do Rio de Janeiro, às quais é possível atribuir em parte, as lacunas de que se revestem suas vantagens competitivas, cruciais no mundo de nossos dias. Igualmente se fez antes menção às perdas sucessivas das terras fluminenses, com a fragilidade econômica das lavouras do café e da cana de açúcar ou do cultivo da laranja, que vieram a encontrar êxito no Estado de São Paulo. Até mesmo fábricas de aguardente, que sustentavam o emprego, em Itaocara, foram transferidas para áreas mais férteis e de maquinário moderno naquela unidade da federação.

Nos dia de hoje, a questão das receitas auferidas pelos "royalties” do petróleo, no Estado do Rio de Janeiro tem mobilizado discurso e opiniões de diferentes setores da sociedade. A possibilidade de perda ou de considerável diminuição de tais recursos configura-se como ameaça crucial para a economia do Estado e dos municípios até então contemplados. De fato, na composição dos respectivos orçamentos, a dependência dessa indenização relativa à produção petrolífera tem correspondido a 79\% em Campos de Goytacazes, a 76\% em Rio das Ostras e a 73\% em Macaé, entre outros, (2002).

Para o Estado do Rio de Janeiro, à perspectiva preocupante de mudança na distribuição dos "royalties" do petróleo se acrescentam os prejuízos decorrentes da perda de impostos (ICMS) sobre o produto, cobrados no destino e não na origem.

Não são poucas as vozes que se levantam contra a excessiva dependência de um recurso finito, como é o petróleo, seja por parte do Estado, seja, principalmente, quanto aos municípios do Norte fluminense. Mas, vale reconhecer que incentivos do governo para determinadas atividades podem conduzir a resultados positivos, desde que efetivamente monitorados e definidos para um determinado lapso de tempo.

É significativo o exemplo do financiamento nacional destinado ao desenvolvimento do parque aeronáutico em São José dos Campos (SP), de que resultaram a Embraer, cujas aeronaves conquistaram venda internacional, e estabelecimento de indústrias de alta tecnologia no município. Um exemplo oposto é o do Norte e do Noroeste fluminenses, regiões onde a quase totalidade das cidades registra baixo nível de vida. Trata-se, portanto, de casos distintos do aproveitamento de incentivos financeiros governamentais, que no centro paulista visaram investimentos de longo prazo, enquanto no Rio de Janeiro, contemplado por décadas com aqueles recursos, foram privilegiados os gastos correntes.

A questão dos “royalties" do petróleo coloca, portanto, em pauta o imperativo de um planejamento econômico integrado para o território do Estado. No tocante à riqueza 
petrolífera, em particular, cabe, certamente, aumentar seu rendimento, acelerando investimentos em prazo compatível, dados a previsível concorrência de novas fontes de energia e pelo caráter finito daquele recurso. Mas, por outro lado, é preciso considerar projetos para outras partes do território, que, em diversos casos, acusam condições econômicas precárias. Não são poucos os municípios fluminenses que deixaram de encontrar alternativa na economia, após a decadência do café e da cana de açúcar.

Na última década, municípios do Norte e Noroeste do Estado, como Cardoso Moreira, Itaocara, Miracema ou mesmo Trajano de Morais, na Zona Serrana, tem registrado perda de população. Em oposição, Rio das Ostras acusou aumento de 165\% e Macaé de 600\%, o que lhes acarreta graves problemas urbanos. A intensa migração de indivíduos rumo à renda do petróleo justificaria, por um lado, a aplicação majoritária da receitas dos "royalties” em gastos correntes.

Para o Estado do Rio de Janeiro, vários problemas são, portanto, colocados em questão, entre os quais: o do movimento migratório, promovido pelas fracas oportunidades de trabalho e renda em diversos municípios; o correspondente esvaziamento demográfico, especialmente das camadas mais ativas da população; e, também, o do esvaziamento territorial, que diz respeito ao desperdício do capital fixo instalado nesses lugares, significando, por exemplo, o fechamento de estabelecimentos comerciais e o de escolas da rede pública.

Mas, outros problemas devem ser igualmente colocados em pauta. Alude-se, por um lado, a necessidade de apurar razões da curta duração ou da falta de fôlego de vários empreendimentos e do desperdício de recursos que representa: assim, a Fábrica Nacional de Motores (FNM), em Duque de Caxias, que produziu um automóvel famoso, o JK, com motor Alfa Romeu, não teve continuidade; de curta duração foram, também, a produção de barrilha e sal da Companhia Nacional de Álcalis, na região de Cabo Frio e a da fábrica de vagões, da Companhia Santa Matilde, em Três Rios. Cabe ainda menção aos CIEPS, introduzidos no governo de L. Brizola, ou ao Teleporto, que sequer chegou a ser inaugurado.

Um problema que decorre diz certamente respeito a condições de emprego e trabalho no conjunto urbano metropolitano do Estado do Rio de Janeiro.

A Nova Economia Política (Northi, in Becker, 2009) tem preconizado Escalas de Ação no sentido de alcançar racionalidade efetiva no crescimento e no emprego, ao longo do território. Uma dessas escalas de ação refere-se ao papel da Área Funcional Urbana, composta pelo núcleo urbano integrado com a área entorno, mediante o trabalho.

Não são estas as condições observadas em cidades fluminenses. Referência especial cabe o papel da grande indústria. Na cidade ou município onde está instalada, essa atividade contribui, de certo, com taxas e impostos para os cofres públicos e com oferta de emprego, basicamente, aos mais qualificados. É preciso reconhecer, porém, que a grande indústria não tem sido pródiga em efeitos multiplicadores, principalmente na criação de novas oportunidades de emprego e renda. Cabe mesmo observar que contribui para elevar os preços do mercado imobiliário local, pressionando a mudança 
de determinadas camadas de moradores para municípios vizinhos, de limitados horizontes econômicos, em geral.

É válido considerar que uma Geografia do Emprego, ou da busca de emprego, tem lugar no território do Estado do Rio de Janeiro: cidades que, cada vez mais, são convertidas em centros dormitórios, e que sustentam movimentos pendulares diários de populações. Multiplicam-se os exemplos, citando-se, entre outros, o de Rio das Ostras, em relação a Macaé e, também o de Campos de Goytacazes, de onde seguem, diariamente, ônibus lotados de trabalhadores para aquela cidade e, em sentido inverso, o fluxo de estudantes que buscam aquele centro tradicional de ensino superior. Referências também cabem aos migrantes diários que partem de Pinheiral, Arrozal, Rio das Flores ou até mesmo de Porto Real rumo ao mercado de trabalho de Volta Redonda. Ou os que, de Paraíba do Sul, Carmo ou Levy Gasparian, se dirigem aos maiores centros próximos, Três Rios e Juiz de Fora, com o mesmo propósito.

Além dos movimentos pendulares diários, devem ser mencionados os da população que trabalha em cidades distantes nos dias úteis e retornam ao lar somente no final da semana. De Paraíba do Sul, por exemplo, parte grande número de transportes lotados, nas madrugadas das segundas- feiras, com destino a São Paulo, Belo Horizonte ou Rio de Janeiro, onde ocupam alojamentos precários e/ou coletivos. A atração do mercado de trabalho metropolitano alcança, portanto, extenso raio de ação e traz, junto, um pesado ônus para o orçamento, dada a necessidade de atendimento desses trabalhadores em serviços diversos, transporte, moradia, saúde e assim por diante, atendimento esse quase sempre deficiente.

Vale, contudo, ressaltar que os problemas, que tanto afetam a situação urbana e metropolitana do Estado do Rio de Janeiro, demandam soluções que não se restringem a um desempenho mais atuante da empresa ou da indústria. Tornam-se cruciais as parcerias com os governos e a participação da sociedade civil.

Iniciativas preliminares estão em curso ou programadas, mas ainda carecem de uma representatividade maior:

- na preocupação com os impactos atuais ou futuros do Complexo Petroquímico do Estado do Rio de Janeiro (Comperj) sobre o local ou em municípios vizinhos, foi constituído um Fórum Comperj, liderado pelo governo do Estado, com a participação da Caixa Econômica Federal, do Banco Nacional de Desenvolvimento Econômico e Social (BNDES) e da sociedade civil, representada por um consórcio de 11 municípios. As tarefas principais são a de promover a urbanização das áreas afetadas pela proximidade daquele empreendimento, com ênfase no saneamento, e a de evitar a formação de bolsões de pobreza, como ocorreu no entorno da Refinaria de Duque de Caxias. A Petrobrás, por sua vez, vem de firmar um convênio com uma agência das Nações Unidas para assentamentos humanos, a ONU-Habitat, visando assegurar o acompanhamento das transformações do entorno do complexo, mediante um elenco de indicadores sociais. É igualmente, de sua competência a implantação de um arco florestal circundando os estabelecimentos do pólo. 
- uma outra iniciativa pode ser reportada no programa de integração urbana ou “integração cidadã”. Apoiado numa parceria firmada entre o governo federal, o estado e o município, ele se destina a algumas das maiores favelas cariocas e visa a contemplálas, com moradia digna, centros de esporte, lazer e saúde e núcleos de geração de renda, no sentido de assegurar inclusão no mercado formal. Vale questionar até que ponto corresponde a um "modelo" de efetiva aplicação, que poderia servir de inspiração para uma organização positiva do entorno das maiores cidades fluminenses, envolvendo a participação ativa da grande empresa.

Tais considerações conduzem à parte finais desse texto.

\section{COMENTÁRIOS FINAIS}

As iniciativas de integração acima, observadas, sinalizaram intenções de ação política conjunta no Estado do Rio de Janeiro, ou mais precisamente, no espaço da região metropolitana.

O desenvolvimento de uma ação política desse porte requer um aprofundamento dos modos de agir, a partir da concepção do território como um todo, que envolve interações do social, do econômico e do ambiental e suas repercussões no urbano metropolitano. É uma compreensão necessária para uma gestão territorial integrada, na qual devem agregar-se responsabilidades conjuntas da empresa, dos governos locais e regionais e da sociedade civil.

Tal concepção do território compatibiliza-se com uma outra escala de ação, igualmente preconizada pela nova economia política: refere-se esta aos recursos que devem ser mobilizados para a instalação de uma Política de Coesão Territorial, no sentido de superar os riscos de uma fragmentação.

Supõe-se que as questões levantadas, ao longo do texto, tenham sinalizado problemas que reclamam, certamente, essas diretrizes de ação.

Uma palavra particular cabe, ainda, à necessidade de restauração política da cidade do Rio de Janeiro. Não se trata de mera evocação nostálgica dos tempos de capital do País, mas de valorizar o acervo cultural e institucional acumulado, incorporando-o numa espiral ascendente. Ao lado de estatais e de importantes fundos de pensão, do BNDES, da Xerox do Brasil e outros, encontram-se aí núcleos científicos de peso. O setor universitário sustenta pesquisas de ponta nas áreas da Física Quântica, das Células Tronco ou da Robótica. Particular projeção detém o Centro de Pesquisa da Petrobrás, junto à UFRJ. Com as perspectivas de exploração do Pré-Sal, crescem possibilidades de instalação de novas empresas e de converter a cidade do Rio de Janeiro em Pólo Inteligente do Petróleo e a ilha do Fundão em uma réplica (tropical) do Vale do Silício.

Por um outro lado, a valorização desses atributos deve ser incorporada como um vetor de capacitação da cidade do Rio de Janeiro na Sociedade do Conhecimento, principal motor da produtividade no mundo globalizado de nossos dias. Um vetor que representa importante vantagem competitiva. 
É preciso, além disso, considerar que a metrópole carioca exerce contínua atração para a realização de importantes eventos científicos. Várias, reuniões têm sido promovidas para discussão de questões relacionadas ao Programa Nuclear Brasileiro, a exemplo do I Seminário de Produção de Hidrogênio Via Nuclear. Ainda, no mês de março de 2010, teve lugar o Fórum Urbano Mundial, promovido pelo grupo Habitat, das Nações Unidas, pela primeira vez na América Latina, e, em paralelo, o Fórum Social Urbano, realização de Movimentos Sociais locais. Deve ser ainda mencionado o Encontro Nacional de Empresários, iniciativa inédita da Academia Brasileira de Ciências, no envolvimento com problemas da economia nacional.

É preciso, portanto, considerar que a cidade do Rio de Janeiro mantém uma representação como Marca em escala mundial, e, esse "capital impalpável” pesou, certamente, na indicação que obteve como lugar de realização das Olimpíadas em 2016.

Um outro comentário diz respeito ao desafio posto para o trabalho da Geografia universitária, em face do imperativo de pesquisa e análise que requer o conhecimento de territorialidades e do território, de maneira geral, de suas potencialidades de desenvolvimento e/ou de conflito. Reveste-se, assim, de suma importância o aprimoramento de conceitos, no sentido mesmo de oferecer bases mais acuradas para a compreensão do mundo real.

Sem a pretensão de esgotar o elenco de atribuições capazes de cobrir o desafio acima colocado, cabe salientar o imperativo de produzir conhecimento que seja incorporado em programas e projetos definidos pelos diferentes níveis de governo, como uma resultante da aproximação entre universidade e estado. De imediato, podem ser colocados em pauta exemplos que evocam a necessidade de apurar conceitos:

- veja-se o estudo da Secretaria de Desenvolvimento do Estado do Rio de Janeiro para um plano de desenvolvimento sustentável para o Norte e Noroeste fluminenses; a idéia do desenvolvimento sustentável tem sido amplamente difundida, sem dispor, no entanto, de uma base conceitual definida, facultando, deste modo, interpretações aleatórias ou "chavões", sem validade para os modos necessários de ação;

- veja-se, ainda, a divulgação de um programa de governo, denominado Território da Cidadania, que deve contemplar 120 municípios no país, tendo como objetivo imediato o de lhes fornecer infraestrutura, principalmente a de saneamento; como se sabe, a falta desses equipamentos constitui um obstáculo para a aplicação do programa federal de habitação, Minha Casa, Minha Vida. Certamente, representa mais um objeto de reflexão e de conceituação, capaz de estender-se ao de Consciência Cidadã, que, no caso do Rio de Janeiro, sinalizaria, seguramente, o imperativo de romper com o conformismo e com a passividade e de construir um novo projeto para o Estado, que inclua a redução da dependência de um recurso natural.

A Geografia, a da Universidade em Particular, tem muito a dizer a respeito e é, deste modo, que deverá se fazer ouvida. 
(*) $\mathrm{O}$ texto corresponde à aula inaugural do $1^{\circ}$ Semestre do Programa de Pós-Graduação em Geografia da Universidade do Estado do Rio de Janeiro (UERJ), em 23/03/2010 - Rio de Janeiro.

Referencias:

ANDRADE, T. , SERRA, R. V. As Cidades Médias do Brasil. Rio de Janeiro. IPEA. (2002).

BERNARDES, L. M. C. “A cidade de Campos e o Norte Fluminense”. In: BERNARDES, J. A. (org.). Rio de Janeiro - Painel de um espaço em crise. Rio de Janeiro, (Igeo/UFRJ). (1987).

BECKER, B-K. O Governo do Território em questão: uma perspectiva a partir do Brasil. Parcerias Estratégicas. Vol. 14 n 28. Brasília. (2009)

CASTELLS, M. A sociedade em redes. (vol. I). Paz e Terra. São Paulo (1993).

CORRÊA, R. L. Origens e tendências da rede urbana: algumas notas. Revista Brasileira de Geografia. Rio de Janeiro, IBGE, v. 56 n. 1/4, jan./dez. ,(1994).

DAVIDOVICH, F. - Escalas da Urbanização: uma perspectiva geográfica do sistema urbano brasileiro. Revista Brasileira de Geografia. IBGE. v. 40, n. 1, jan./mar. Rio de Janeiro, (1978).

- Metrópole e Território: metropolização do espaço no Rio de Janeiro. Cadernos Metrópole n. 6, $2^{\circ}$ sem. Rio de Janeiro, (2001).

- A “volta da metrópole” no Brasil: referências para a gestão territorial, in: Metrópoles: Entre a coesão e fragmentação, a cooperação e o conflito. Luiz César de Q. Ribeiro (org.) São Paulo. FASE, Observatório das Metrópoles. Ed. Fund. Perseu Abramo. Rio de Janeiro, (2004).

GUATTARI, F. Espaço e Poder: a criação de territórios na cidade. Espaço e Debates, ano V, n. 16, São Paulo, (1985).

HALL, P. , Pain, K. The polycentric metropolis: Learning from mega-city regions in Europe. London. Earthscan, (2006).

IBGE - Regiões de Influência de Cidades Brasileiras. Coordenação de Geografia. IBGE. Rio de Janeiro, (2007).

LEFÉBVRE, H. La Revolution Urbaine. Gallimard, Paris, (1970).

La prodution de l'espace. Paris, Authropos, (1974).

LIMONAD, E. Das hierarquias urbanas à cooperação entre lugares: a reestruturação produtiva e a formação de novas territorialidades no Sul Fluminense. Anpur. Porto Alegre, (1999).

MESENTER, I. -Esvaziamento econômico do Rio de Janeiro. Cadernos IPPUR/UFRJ, VII, n. 2, Rio de Janeiro, (1993).

MONIÉ, F. - Logística de transporte, modernização portuária e inserção competitiva do Rio de Janeiro na economia global. Território. n. 10. , jan./jun. Laget/UFRJ. Rio de Janeiro, (2001).

O GLOBO - Várias edições (2009, 2010). Rio de Janeiro. 
PACHECO, C. A. Fragmentação da Nação. Unicamp. Campinas, (1998).

RIBEIRO, L. C. Q. Conferência de abertura. Seminário: Metrópole: entre a coesão social e o conflito; entre a cooperação e a fragmentação. Observatório de Políticas Urbanas e Gestão Municipal. Rio de Janeiro, (2002).

ROCHEFORT, M. Redes e sistemas. Ensinando sobre o urbano e o regional. Hucitec. São Paulo, (1998).

SANTOS, M. “O retorno do território”. In: SANTOS, M. et al (org.). Território, Globalização e Fragmentação. Hucitec/ Anpege. São Paulo, (1994).

A Natureza do Espaço: técnica e tempo, razão e emoção. Hucitec. São Paulo, (1998).

SASSEN, S. Cidade Global. In: LAVINAS, L. et al (org.). Reconstrução do espaço urbano e regional no Brasil. Hucitec. São Paulo, (1993).

SCOTT, A. et al Regiões Globais. Espaço \& Debates. n. 41. São Paulo, (2000).

VALOR ECONÔMICO. Várias edições (2009, 2010). São Paulo.

VELTZ, P. Mondialisation, Villes et Territoires. Paris Presses Universitaires de France (1996).

Enviado para publicação em julho de 2010.

Aceito para publicação em agosto de 2010. 